\title{
BMJ Open Adverse effects information in clinical guidelines on pharmacological treatment of depression in children and adolescents: a systematic review
}

\author{
Tone Westergren (D) , ${ }^{1,2}$ Sigrid Narum, ${ }^{3}$ Marianne Klemp ${ }^{2}$
}

To cite: Westergren T, Narum S, Klemp M. Adverse effects information in clinical guidelines on pharmacological treatment of depression in children and adolescents: a systematic review. BMJ Open 2020;10:e036412. doi:10.1136/ bmjopen-2019-036412

- Prepublication history and additional material for this paper are available online. To view these files, please visit the journal online (http://dx.doi org/10.1136/bmjopen-2019036412).

Received 13 December 2019 Revised 15 April 2020 Accepted 20 May 2020
Check for updates

(C) Author(s) (or their employer(s)) 2020. Re-use permitted under CC BY-NC. No commercial re-use. See rights and permissions. Published by BMJ.

${ }^{1}$ Regional Medicines Information and Pharmacovigilance Centre (RELIS Sør-Øst), Dept. of Pharmacology, Oslo University Hospital, Oslo, Norway

${ }^{2}$ Dept. of Pharmacology, Institute of Clinical Medicine, University of Oslo, Oslo, Norway

${ }^{3}$ Center for

Psychopharmacology,

Diakonhjemmet Hospital, Oslo, Norway

Correspondence to

Tone Westergren;

twesterg@ous-hf.no

\section{ABSTRACT}

Objectives To analyse to what extent clinical practice guidelines on drug treatment of depression in children and adolescents mention the risk of adverse effects, to characterise the citations in the guidelines and to assess to what extent data from a major study (Treatment for Adolescents With Depression Study, TADS) was used as basis for information about adverse effects.

Design Systematic review of clinical guidelines and clinical decision support tools.

Data sources PubMed, EMBASE, guideline collections, Health libraries.

Eligibility criteria We included national guidelines on depression in children and adolescents from European and/ or English-speaking countries, published in English, German, French or any Scandinavian language since 2008. We also included well-known, international clinical decision support tools.

Data extraction and synthesis Guidelines were examined by all authors to identify and classify information on adverse effects. Citations for statements on adverse effects were extracted and classified by category. The extent of citations about suicidality risk versus other adverse effects was assessed.

Results 19 guidelines were assessed. All guidelines discussed risk of suicidal behaviour connected with use of antidepressants. Most guidelines mentioned some other psychiatric adverse effects. Several guidelines did not include information on well-known and common somatic adverse effects. Most references concerned risk of suicidality. Adverse effects identified in underlying studies were not always presented. The TADS study was referred to, directly or indirectly, by 18/19 guidelines, but some only referred to TADS with regard to suicidality without citing the study's findings of somatic adverse effects. No guideline commented on the lack of long-term adverse effects data from TADS. Conclusions Guidelines for treatment of depression in children and adolescents vary widely regarding information on adverse effects. Many guidelines do not provide information on common somatic adverse effects. There is no consensus as to what extent risks of adverse effects connected with use of antidepressants should be described in guidelines.

\section{INTRODUCTION}

The use of antidepressants in children and adolescents with depression is the topic of
Strengths and limitations of this study

- The search for guidelines was extensive.

- Inclusion of guidelines was not limited to English texts.

- The main limitation is that some guidelines may have been overlooked and that the cut-off for guideline inclusion can be debated on a geographical and local level.

- The guideline committee mandate and scope may have varied between guidelines.

- Guidelines were searched for all relevant statements about adverse effects and corresponding citations, but some statements or text excerpts may have been overlooked.

several national and international guidelines which appear to differ considerably in extent, quality and information on potential harms.

As defined by the US Institute of Medicine in 2011, clinical practice guidelines are statements that include recommendations intended to optimise patient care that are informed by a systematic review of evidence and an assessment of the benefits and harms of alternative care options. Guidelines should provide a clear description of potential benefits and harms for each recommendation. ${ }^{12}$ However, compliance with standards has been shown to be low for several parameters, including more focus on benefits than on potential harms. ${ }^{3}$ Other researchers have assessed the quality of clinical guidelines regarding benefits of antidepressants ${ }^{45}$ using the Appraisal of Guidelines for Research\& Evaluation II (AGREE II) tool. ${ }^{6}$ We have not identified any specific appraisals of the adverse effects information provided in guidelines on antidepressant therapy.

For fluoxetine, which is the suggested medication of first choice, few high-quality 
clinical trials are available to assess risk-benefit. ${ }^{7}$ The largest randomised controlled clinical trial on fluoxetine in children and adolescents with depression is a National Institute of Mental Health (NIMH)-funded study (Treatment for Adolescents With Depression Study (TADS) $),{ }^{8}$ which is considered a high-quality trial. ${ }^{9}$ We have previously analysed the adverse effects reporting in the TADS study ${ }^{10}$ and found that little data had been published concerning adverse effects profile during treatment for more than 12 weeks, with the exception of suicidality.

Based on our previous study, ${ }^{10}$ we had reason to believe that adverse effects descriptions in many guidelines on treatment of depression in children and adolescents would focus primarily on suicidality, with less attention given to the risk of other adverse effects and the riskbenefit balance. The adverse effects profile of the most commonly used medications, the selective serotonin reuptake inhibitors (SSRIs), is generally assumed to be similar in adults and children/adolescents and similar between the different SSRIs. This includes psychiatric effects such as suicidality, mania, anxiety, agitation and sleep disorders, as well as gastrointestinal effects such as nausea, diarrhoea and anorexia/weight loss. In this review, we aimed to analyse to what extent adverse effects data on SSRIs were mentioned in clinical practice guidelines on treatment of depression in children and adolescents. We also aimed to characterise the documentation provided as references in the clinical guidelines, and to assess to what extent data from the TADS study, with the identified data gaps, was used as basis for information about adverse effects.

\section{METHODS}

To identify guidelines and clinical evidence summarisations on treatment of depression in children and adolescents, a search was performed according to the Norwegian Health Library guidelines on literature searches for development of clinical procedures. ${ }^{11}$

\section{Literature database search}

Searches in PubMed and guideline collections were carried out in the period 30 October 2018 to 17 February 2019. An EMBASE search with time limits 2008-2019 was performed 5 December 2019.

Several PubMed searches were performed, using the search terms:

- ("depressive disorder" [MeSH Terms] OR ("depressive"[All Fields] AND "disorder"[All Fields]) OR "depressive disorder"[All Fields] OR "depression"[All Fields] OR "depression" [MeSH Terms]) AND (("guideline"[Publication Type] OR "guidelines as topic"[MeSH Terms] OR "guideline"[All Fields]) OR ("practice guideline"[Publication Type] OR "practice guidelines as topic"[MeSH Terms] OR "clinical practice guideline"[All Fields])) AND ("humans" [MeSH Terms] AND ("infant" [MeSH
Terms] OR “child"[MeSH Terms] OR "adolescent" [MeSH Terms]))

- "Depressive Disorder/drug therapy"[MAJR] AND "Antidepressive Agents/therapeutic use"[MAJR] AND (Guideline[ptyp] OR Practice Guideline[ptyp])

- ((practice guidelines as topic) AND adolescent psychiatry) AND depressive disorder

Filters: Humans, Child: birth-18 years

EMBASE search terms were: (exp adolescent depression/ OR exp major depression/ OR exp depression/) AND practice guideline/. Limits: (child <unspecified age $>$ or adolescent $<13$ to 17 years $>$ ) and $y r=“ 2008-2019 "$

\section{Searches in clinical guidelines collections}

Clinical treatment guidelines were identified through searches in Guidelines International Network, McMaster Plus, Epistemonikos, UpToDate, BMJ Best Practice, DynaMed Plus, International Network of Agencies for Health Technology Assessment, National Institute for Health and Care Excellence (UK), Cochrane library, the Norwegian Health Library, Sundhetsstyrelsen (Denmark), Socialstyrelsen (Denmark), Center for Clinical Guidelines (Denmark), Socialstyrelsen (Sweden), AHRQ website (USA), IQWIQ website (Germany), Psychenet website (Germany), guidelines.gov (USA), SIGN website (Scotland), Health Canada website, CADTH website (Canada). In addition, a manual reference search was performed on identified studies and guidelines. The guideline search and selection process is described in a Preferred Reporting Items for Systematic Reviews and Meta-Analyses (PRISMA) flow chart. ${ }^{12}$

\section{Inclusion and exclusion criteria}

We included national guidelines from European and/ or English-speaking countries, published in English, German, French and any Scandinavian language since 2008, covering the last 10 years. We also included wellknown and widely used international decision support tools. Local hospital or county guidelines were not included.

The guidelines and decision support tools (hereafter referred to as guidelines) should specifically address depression in children and adolescents. In cases where we retrieved multiple guidelines from the same organisation, the most recent version was analysed.

\section{Data extraction}

The guidelines were examined to identify information on safety or adverse effects. All authors made an overall assessment of the full guidelines. Text excerpts and corresponding references concerning safety or adverse effects were initially extracted by TW. Data extraction from all guidelines was checked by SN and MK. Text excerpts were assessed in detail by all authors. Information on adverse effects provided in each guideline was analysed and classified by organ system, in accordance 
with the classification used in the product monograph for Prozac (fluoxetine) by Eli Lilly. ${ }^{13}$ In order to distinguish suicidality or self-harm from other psychiatric adverse effects, these were registered as a separate category. Analysis was limited to adverse effects occurring during treatment and did not include mention of withdrawal reactions.

We assessed whether the guidelines provided information on the quality of the underlying evidence (high, moderate, low or very low) and strengths of recommendations (strong or weak) by use of the Grading of Recommendations Assessments, Development, and Evaluation (GRADE) tool $^{1415}$ or similar criteria for quality ratings.

We also evaluated the guidelines regarding presentation and risk-benefit assessment. To our knowledge, there are no explicit criteria for such evaluations. The guidelines were assessed by all authors independently, according to whether the guideline provided an overall discussion on risks, made an attempt to assess risks and benefits together, gave information on handling adverse effects, provided frequency estimates on risks or gave recommendations on monitoring patients. Any discrepancies in judgement were discussed by all authors.

\section{Classification of adverse effects}

References that were provided as basis for statements on adverse effects were extracted from all guidelines, and the most cited references were identified. Adverse effects were mainly classified by System Organ Class according to the MedDRA classification, as used in European Summaries of Product Characteristics. ${ }^{16}$ In this classification, appetite disorders are classified under Metabolism and nutrition disorders; sleep disorders, restless, anxiety, mania and mood disorders are classified under psychiatric disorders and headache, dizziness, and somnolence are classified under nervous system disorders. Suicidal thoughts and behaviour are classified under psychiatric disorders in MedDRA, but has been noted separately in this review. Reproductive system and breast disorders include sexual dysfunction and erectile and ejaculation disorders. Libido changes are classified under Psychiatric disorders in MedDRA, we have, however, included any such information in the Reproductive system and breast disorders category, in order to show a comprehensive view on all sexual adverse effects. An overview of the System Organ Classes and the included adverse effects can be found in the online supplementary material table $\mathrm{S} 1$.

The references were assessed and classified by category. Analysis by category and type of adverse effects was performed to assess to what extent the citations were used to discuss risk of suicidality versus other adverse effects.
Patient and public involvement

No patients were involved in this review.

\section{RESULTS}

\section{Inclusion of guidelines}

Nineteen guidelines were included in the final analysis (table 1). A PRISMA flow diagram describing the search and screening process is shown in figure 1.

\section{Adverse effects mentioned in guidelines}

We identified 20 adverse effects categories in the summary of product characteristics for Prozac. ${ }^{13}$ The guidelines' mention of these adverse effects categories were highly variable (table 2).

The 19 guidelines mentioned an average of 5.3 adverse effects categories (median 4.0, range 1-15). All 19 guidelines included information on suicidal risk. Fifteen of 19 mentioned other types of psychiatric adverse reactions, including mention of manic switching or manic/hypomanic episodes in seven guidelines.

Seven of 19 guidelines limited their information on adverse effects to suicidality and/or psychiatric reactions. Three guidelines mentioned risk of suicidal behaviour only (figure 2). Nervous system adverse effects including headache was mentioned by $10 / 19$ guidelines, as was also the case for gastrointestinal reactions. Several possible adverse effects were only mentioned in a few guidelines, as an example, the risk of sexual adverse effects was mentioned in $5 / 19$ guidelines. Four guidelines mentioned adverse effects in 10 organ categories or more. ${ }^{17-20}$

The overall assessments of somatic and nervous adverse effects varied widely, as illustrated by different descriptions of the SSRI risk profile. While one guideline stated that studies have shown somatic adverse effects to have small significance, ${ }^{21}$ another guideline stated that SSRI treatment causes significantly more nausea, diarrhoea, anorexia and stimulatory side effects (agitation, insomnia and anxiety) than tricyclic antidepressants. ${ }^{22}$ In our evaluation of the guidelines regarding presentation and risk-benefit assessment, we judged that $9 / 19$ guidelines could be classified as having a sufficiently extensive and balanced consideration of adverse effects in their overall recommendations, while 10 guidelines did not (see online supplementary material table S2). Nine of 19 guidelines presented grading of evidence and strength of recommendations by the GRADE tool or similar, though the evidence grading mostly reflected efficacy documentation (see online supplementary material table S3).

\section{References in guidelines as basis for adverse effects information}

We identified 124 specific references as basis for statements in the 19 guidelines (see online supplementary material table S4). Some guidelines mentioned general sources of information, such as 'FDA warnings', 'Cochrane reviews', or 'Product monographs'. The guidelines had a mean number of adverse effects references of 9.3 (range 0-32). 


\begin{tabular}{|c|c|c|c|c|}
\hline Title & Publisher & Country & Year & Category \\
\hline $\begin{array}{l}\text { Guidelines for Adolescent Depression in } \\
\text { Primary Care: Part II. Treatment, Ongoing } \\
\text { Management. }\end{array}$ & American Academy of Pediatrics & USA & 2018 & Guideline \\
\hline Depression in children and adolescents. ${ }^{31}$ & DynaMed Plus, EBSCO Health & USA & 2018 & $\begin{array}{l}\text { Decision support } \\
\text { tool }\end{array}$ \\
\hline $\begin{array}{l}\text { Clinical Guidelines for the Management } \\
\text { of Adults with Major Depressive Disorder: } \\
\text { Section } 6 .{ }^{32}\end{array}$ & $\begin{array}{l}\text { Canadian Network for Mood and Anxiety } \\
\text { Treatments }\end{array}$ & Canada & 2016 & Guideline \\
\hline $\begin{array}{l}\text { Anxiety and Depression in Children and } \\
\text { Youth - Diagnosis and Treatment. }{ }^{18}\end{array}$ & $\begin{array}{l}\text { British Columbia Guidelines Protocols } \\
\text { Advisory Committee }\end{array}$ & Canada & 2010 & Guideline \\
\hline $\begin{array}{l}\text { Evidence-based guidelines for } \\
\text { treating depressive disorders with } \\
\text { antidepressants. }{ }^{22}\end{array}$ & $\begin{array}{l}\text { British Association for } \\
\text { Psychopharmacology }\end{array}$ & UK & 2015 & Guideline \\
\hline Treating depression in young people. ${ }^{34}$ & $\begin{array}{l}\text { Orygen National Centre of Excellence in } \\
\text { Youth Mental Health }\end{array}$ & Australia & 2017 & Guideline \\
\hline $\begin{array}{l}\text { Identification of Common Mental } \\
\text { Disorders and Management of Depression } \\
\text { in Primary Care. }{ }^{35}\end{array}$ & $\begin{array}{l}\text { New Zealand Guidelines Group/Ministry } \\
\text { of Health }\end{array}$ & New Zealand & 2008 & Guideline \\
\hline $\begin{array}{l}\text { Manifestations dépressives à } \\
\text { I'adolescence : repérage, diagnostic, prise } \\
\text { en charge en soins de premier recours. }{ }^{19}\end{array}$ & Haute Authorité de Santé & France & 2014 & Guideline \\
\hline $\begin{array}{l}\text { Vejledning om medikamentel behandling } \\
\text { af børn og unge med psykiske lidelser. }{ }^{38}\end{array}$ & Danish Health Authority & Denmark & 2013 & Guideline \\
\hline $\begin{array}{l}\text { Landsdækkende klinisk retningslinje } \\
\text { vedrørende udredning og behandling af } \\
\text { depression hos børn og unge. }{ }^{39}\end{array}$ & Børne-og Ungdomspsykiatrisk Selskab & Denmark & 2011 & Guideline \\
\hline $\begin{array}{l}\text { Nationella riktlinjer för vård vid depression } \\
\text { och ångestsyndrom. }{ }^{21}\end{array}$ & The National Board of Health and Welfare & Sweden & 2017 & Guideline \\
\hline Childhood depression. ${ }^{40}$ & EBM Guidelines Duodecim & Finland & 2018 & Guideline \\
\hline Depression of adolescents. ${ }^{25}$ & EBM Guidelines Duodecim & Finland & 2018 & Guideline \\
\hline
\end{tabular}

EBM, evidence based medicine; NICE, National Institute for Health and Care Excellence.

The 124 references were cited 177 times, as some references had multiple citations (table 3). The largest group of references was single studies, followed by review articles, statements or warnings from medicinal authorities and systematic reviews (see online supplementary material table S4). Most references to review articles, authorities, systematic reviews and guidelines concerned risk of suicidality. For the single studies, however, 22/52 citations $(42,3 \%)$ referred to adverse effects in other organ systems (see online supplementary material table S4). These included 14 clinical trials. Somatic adverse effects were referred to in 3.2 organ categories for each citation (mean value), minimum value 1 , maximum value 10 .

Forty-one of 177 citations concerned adverse effects other than suicidality and/or other psychiatric adverse effects (see online supplementary material table S4). Most of those referred to somatic adverse effects in few organ systems (mean value 2.8, median 2.0, minimum value 1 , maximum value 10 ).

Overall, 116 citations concerned risk of suicidal behaviour and 54 citations concerned risk of other psychiatric adverse effects, while fewer citations 


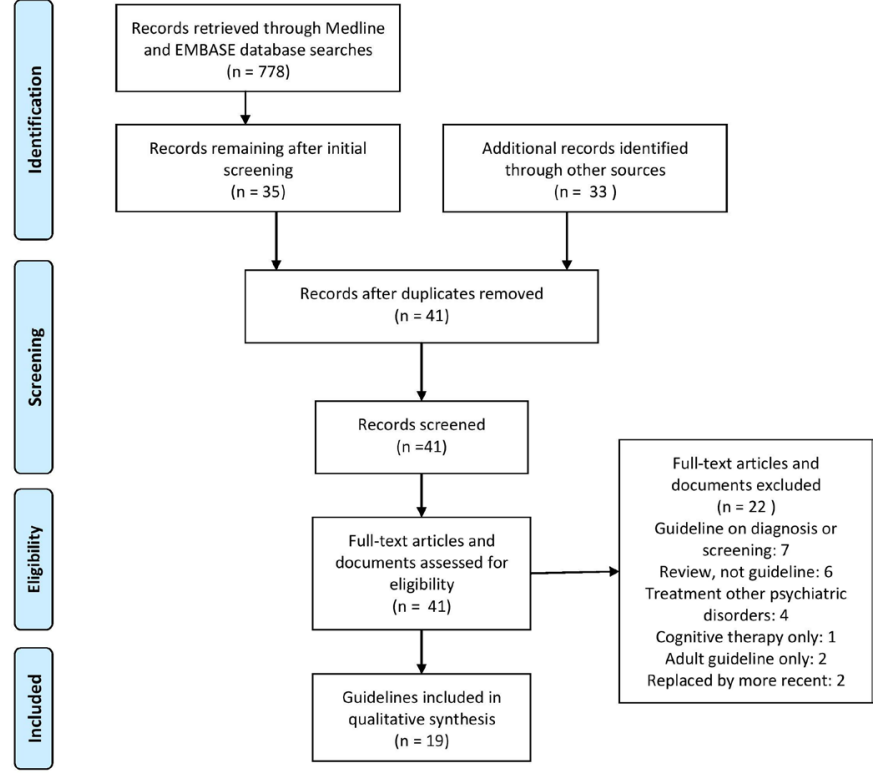

Figure 1 Identification of guidelines for treatment of depression in children and adolescents. PRISMA flowchart. PRISMA, Preferred Reporting Items for Systematic Reviews and Meta-Analyses.

concerned somatic adverse effects. For some known adverse effects according to the product monograph, ${ }^{13}$ no guidelines provided any citations (figure 3 ).

\section{Data from the TADS study as basis for information about} adverse effects

Of the 19 guidelines, seven referred directly to publications from the TADS study, while 11 referred to sources that cited TADS as part of their assessment. One guideline did not provide any references and consequently did not refer to the TADS study.

Adverse effects data from the TADS study were published by March $e t a l^{8}$ and in more detail by Emslie et al in 2006. ${ }^{23}$ Both publications describe a broad range of adverse effects, including risk of suicidal behaviour, psychiatric adverse effects such as mania, sedation or sleeping problems, abdominal pain, diarrhoea and vomiting during the first 12 weeks of treatment. These articles were cited by seven and two guidelines, respectively. Most guidelines referring to TADS, directly or indirectly, described psychiatric, nervous, gastrointestinal and respiratory adverse effects. However, three guidelines $^{202425}$ that cited the TADS publication from March $2004^{8}$ did not cite the study's findings of somatic adverse effects. No guideline commented on the lack of long-term adverse effects data from TADS beyond 12 weeks.

\section{DISCUSSION}

Our analysis of 19 treatment guidelines of depression in children and adolescents shows that the guidelines vary widely regarding information on adverse effects. The most commonly used medications, the SSRIs, may have multiple adverse effects involving several organ systems, but few guidelines described the full adverse effect profile. Several guidelines mentioned only risk of suicidal behaviour with or without mention of other psychiatric adverse effects. In many guidelines where adverse effects are mentioned, the frequency or the benefit-risk assessment is missing. Overall, somatic adverse effects were mentioned to little extent in the guidelines, and mention was often limited to few organ systems. The reporting of adverse effects in the guidelines appears to be selective and arbitrary. Several guidelines give the impression that suicidality is the only safety issue of consequence, and that there is a minor and limited risk of other adverse effects. We have not been able to identify a current, accepted standard for inclusion of adverse effects information in guidelines. It is possible that the varying descriptions of adverse effects in the guidelines are due to a lack of consensus as to what should be included. It can be argued that a full spectrum of adverse effects should be described. However, limitations may be necessary due to readability and format, in which case selection criteria should be stated.

All guidelines indicated suicidality as a major risk factor, reflecting that this has been a major topic of safety discussions. This was also the case for the underlying literature references. Most citations concerned suicidality with or without other psychiatric adverse effects. Far fewer citations concerned adverse effects in other organ systems. The fact that most references to review articles, authorities, systematic reviews and guidelines concerned risk of suicidality indicate that suicidality risk has been the main focus when addressing adverse effects of SSRIs. There were indications of selective citing, where the underlying articles provided more details of adverse effects than was referred to in the guidelines. The most frequently cited reference, the Cochrane database review by Hetrick $e t a l,{ }^{7}$ provides details on several adverse effects observed in the included studies, but most guidelines referred to this review only in the context of suicidality risk. Likewise, the TADS publication by March $e t a l^{8}$ describes several somatic adverse effects which were not mentioned in many guidelines that cited the study on suicidality risk. A later publication on the range of adverse effects observed in the TADS study ${ }^{23}$ was cited by two guidelines only. We found that most of the known somatic adverse effects were not mentioned in the majority of the guidelines, thereby giving users a biased and skewed impression of the risk of harms. This lack of adverse effect information may affect treatment of children and adolescents with depression.

Guidelines should include descriptions of benefits and harms for the recommendations, however, this is a general statement and does not specify to what extent possible harms and adverse drug reactions should be described. The recommended tool for assessment of guideline quality, the AGREE II tool ${ }^{6}$ includes the criterion 'The health benefits, side effects and risks 


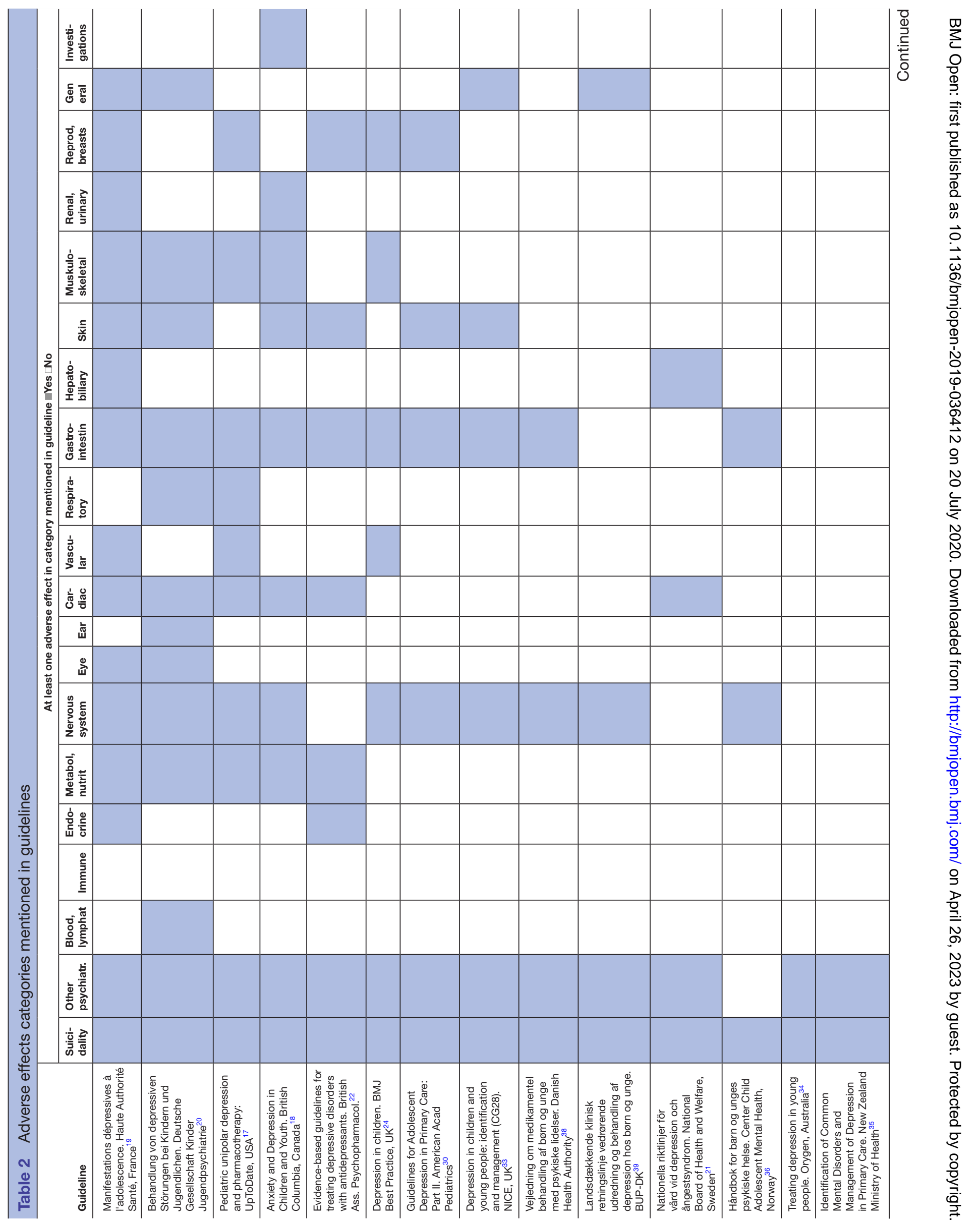




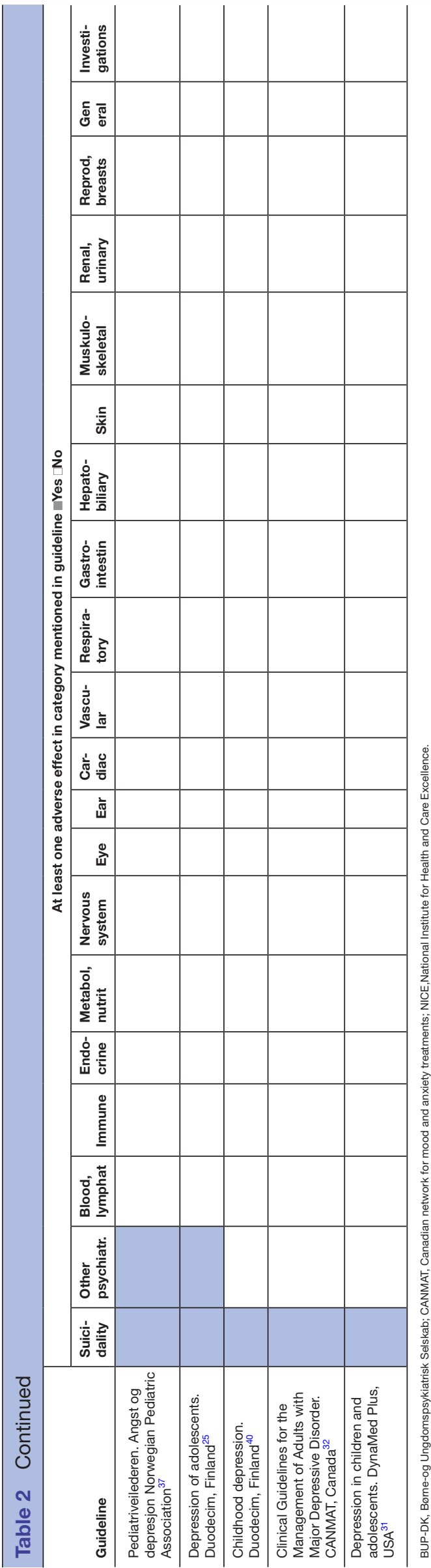

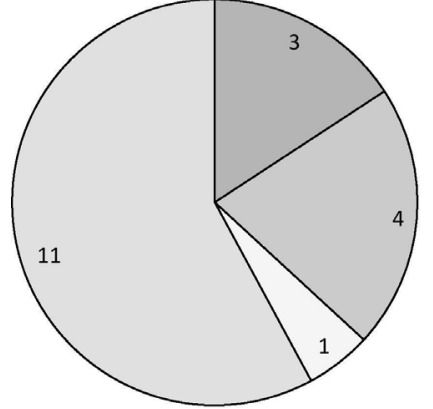

口Suicidality only

$\square$ Suicidality and at least one other psychiatric $\mathrm{AE}$

$\square$ Suicidality and at least one AE in other organs

$\square$ Suicidality, at least one psychiatric $\mathrm{AE}$, and at least one $\mathrm{AE}$ in other organs

Figure 2 Information on adverse effects (AE) in clinical treatment guidelines $(n=19)$.

have been considered in formulating the recommendations'. This should include descriptions of supporting data and reports of side effects, reports of the balance between benefits and side effects, and recommendations reflecting considerations of both benefits and side effects. ${ }^{26}$ The tool does not, however, specify what should be considered a sufficient level of risk information. We have not identified any quality assessment studies of adverse effect information in clinical guidelines.

For systematic reviews, which sum up the literature and form a basis for guidelines, a framework has been proposed to include relevant harms data in a more comprehensive way. ${ }^{27}$ However, research still show failings in the reporting of harms in systematic reviews. ${ }^{28} 29$ Despite having procedures and checklists for developing guidelines, there is no guarantee that adverse effects identified in underlying clinical trials will be reflected in the finished guideline.

In conclusion, we found that many guidelines on treatment of depression in children and adolescents did not provide a thorough risk assessment with information on well-known and common adverse effects. There is currently no international standard regarding the extent of adverse effects information that should be included in guidelines. Development of such standards would give clinicians better accounts of risks and benefits as basis for therapy decisions.

\section{Strengths and limitations}

We conducted an extensive search for guidelines, however, some older guidelines were not found in electronic full text due to closure of the US National Guideline Clearinghouse. In many cases, we were able to identify updates that were available elsewhere. Inclusion of guidelines was not limited to English texts. Due to our geographical location and language issues, many included guidelines are of European or American origin. The cut-off for guideline inclusion can be debated on a geographical and local level. We have included guidelines on a national level, but did not aim to include guidelines from all countries. Local hospital or county guidelines were not included. There is, however, a possibility that we have not identified all relevant guideline collections, and that some guidelines may have been overlooked. We included 
Table 3 Most cited references

\section{Reference}

Hetrick SE, McKenzie JE, et al. Newer generation antidepressants for depressive disorders in children and 9 adolescents. Cochrane Database $2012^{7}$

March J, Silva S, et al. Fluoxetine, cognitive-behavioral therapy, and their combination for adolescents with depression: Treatment for Adolescents With Depression Study (TADS) randomized controlled trial. JAMA $2004^{8}$

Bridge JA, lyengar S, et al. Clinical response and risk for reported suicidal ideation and suicide attempts in 6 pediatric antidepressant treatment: a meta-analysis of randomized controlled trials. JAMA $2007^{41}$

NICE 2015:CG28 Depression in children and young people: identification and management in primary, 5 community and secondary care ${ }^{33}$

Barbui C, Esposito E, Cipriani A. Selective serotonin reuptake inhibitors and risk of suicide: a systematic 5 review of observational studies. CMAJ $2009^{42}$

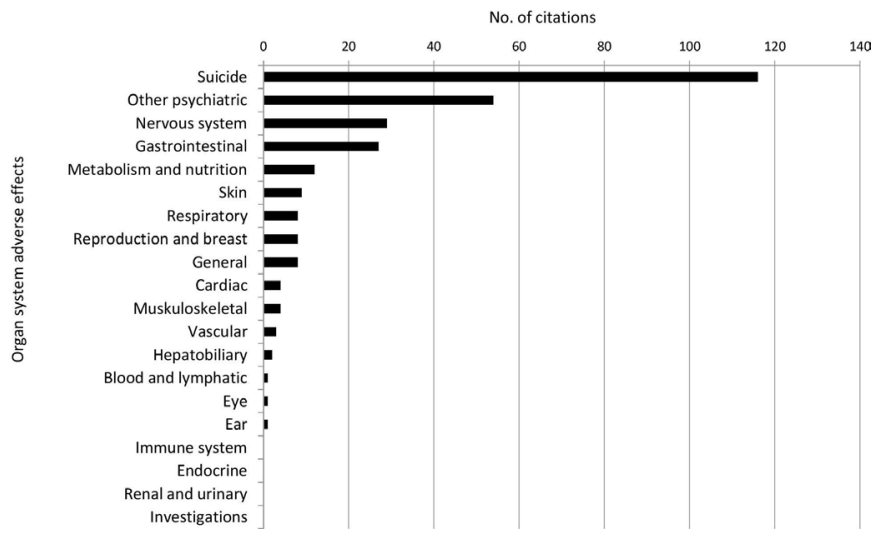

Figure 3 Number of citations in guidelines as basis for statements on adverse effects in organ systems.

three well-known, international decision support tools as they are probably being used by professionals to an increasing extent, however, other similar tools may be commercially available. Guidelines were examined for text extracts concerning adverse effects, and the corresponding reference was noted. We cannot exclude the possibility that some statements or references may have been overlooked. Finally, we did not aim to perform a formal assessment of the overall quality of the guidelines and cannot assess whether this is correlated with the extent of adverse effects information provided in the guideline. It is possible that guideline committee mandates and local expectations varied between guidelines.

Contributors The research question was developed by all authors. All authors discussed and defined the project. TW researched the literature and made the initial assessments. All authors discussed the guidelines included in the study, including interpretation and classification of information in the guidelines. TW drafted and finalised the manuscript as lead author. SN and MK commented on the draft and revised the manuscript at all stages.

Funding The authors have not declared a specific grant for this research from any funding agency in the public, commercial or not-for-profit sectors.

Competing interests None declared.

Patient consent for publication Not required.

Provenance and peer review Not commissioned; externally peer reviewed.
Data availability statement Data are available on reasonable request. Tables of references used in guidelines and their corresponding text statements are available on request.

Open access This is an open access article distributed in accordance with the Creative Commons Attribution Non Commercial (CC BY-NC 4.0) license, which permits others to distribute, remix, adapt, build upon this work non-commercially, and license their derivative works on different terms, provided the original work is properly cited, appropriate credit is given, any changes made indicated, and the use is non-commercial. See: http://creativecommons.org/licenses/by-nc/4.0/.

ORCID iD

Tone Westergren http://orcid.org/0000-0002-4990-062X

\section{REFERENCES}

1 Institute of Medicine (US). Committee on standards for developing trustworthy clinical practice guidelines. clinical practice guidelines we can trust. Washington DC: National Academies Press (US), 2011.

2 Shekelle P. Overview of clinical practice guidelines, 2019. Available: https://www.uptodate.com/contents/overview-of-clinical-practiceguidelines? search=guidelines\&source=search_result\&selectedTitle= 1 150\&usage_type $=$ default\&display_rank=1\#H7 [Accessed 24 Jun 2019].

3 Kung J, Miller RR, Mackowiak PA. Failure of clinical practice guidelines to meet institute of medicine standards: two more decades of little, if any, progress. Arch Intern Med 2012;172:1628-33.

4 Bennett K, Courtney D, Duda S, et al. An appraisal of the trustworthiness of practice guidelines for depression and anxiety in children and youth. Depress Anxiety 2018;35:530-40.

5 Zafra-Tanaka JH, Goicochea-Lugo S, Villarreal-Zegarra D, et al. Characteristics and quality of clinical practice guidelines for depression in adults: a scoping review. BMC Psychiatry 2019;19:76.

6 Brouwers MC, Kho ME, Browman GP, et al. AGREE II: advancing guideline development, reporting and evaluation in health care. CMAJ 2010;182:E839-42.

7 Hetrick SE, McKenzie JE, Cox GR, et al. Newer generation antidepressants for depressive disorders in children and adolescents. Cochrane Database Syst Rev 2012;11:Cd004851.

8 March J, Silva S, Petrycki S, et al. Fluoxetine, cognitive-behavioral therapy, and their combination for adolescents with depression: treatment for adolescents with depression study (TADS) randomized controlled trial. JAMA 2004;292:807-20.

9 Walkup JT. Antidepressant efficacy for depression in children and adolescents: Industry- and NIMH-funded studies. Am J Psychiatry 2017:174:430-7.

10 Westergren T, Narum S, Klemp M. Critical appraisal of adverse effects reporting in the 'treatment for adolescents with depression study (TADS)'. BMJ Open 2019;9:e026089.

11 The Norwegian Electronic Health Library. Litteratursøk. Available: http://www.helsebiblioteket.no/fagprosedyrer/lage-og-oppdaterefagprosedyrer/litteratursok [Accessed Jan 2019].

12 Moher D, Liberati A, Tetzlaff J, et al. Preferred reporting items for systematic reviews and meta-analyses: the PRISMA statement. BMJ 2009;339:b2535. 
13 Datapharm. Summary of product characteristics; Prozac: Eli Lilly and Company Limited, 2018. Available: https://www.medicines.org.uk/ emc/product/3768/smpc\#PRODUCTINFO [Accessed 31 May 2018].

14 Guyatt G, Oxman AD, Akl EA, et al. GRADE guidelines: 1. Introduction-GRADE evidence profiles and summary of findings tables. J Clin Epidemiol 2011;64:383-94.

15 Andrews J, Guyatt G, Oxman AD, et al. GRADE guidelines: 14. going from evidence to recommendations: the significance and presentation of recommendations. J Clin Epidemiol 2013;66:719-25.

16 European Commission. A guideline on summary of product characteristics (SmPC), 2009. Available: https://ec.europa.eu/health/ documents/eudralex/vol-2_en

17 Moreland CS, Bonin L. Pediatric unipolar depression and pharmacotherapy: choosing a medication, 2019. Available: https:// www.uptodate.com/contents/pediatric-unipolar-depression-andpharmacotherapy-choosing-a-medication [Accessed 14 Feb 2019].

18 Guidelines \& Protocols Advisory Committee, Medical Services Commission, British Columbia. Anxiety and depression in children and youth-diagnosis and treatment. British Columbia: British Columbia Medical Association, Ministry of Health Services, 2010. https://www2.gov.bc.ca/gov/content/health/practitioner-professionalresources/bc-guidelines/anxiety-and-depression-in-youth

19 HAS - Haute Authorité de Santé. Manifestations dépressives I'adolescence: repérage, diagnostic et prise en charge en soins de premier recours, 2014. Available: https://www.has-sante.fr/portail/ $\mathrm{jcms} / \mathrm{c}$ 1782013/fr/manifestations-depressives-a-l-adolescencereperage-diagnostic-et-prise-en-charge-en-soins-de-premier-recours [Accessed 17 Feb 2019].

20 Arbeitsgemeinschaft der Wissenschaftlichen Medizinischen Fachgesellschaften. Behandlung von Depressiven Störungen bei Kindern und Jugendlichen, 2013. Available: https://www.awmf.org/ leitlinien/detail/I/028-043.html [Accessed 31 Jan 2019]

21 Socialstyrelsen. Nationella riktlinjer för vård vid depression och ångestsyndrom. Egentlig depression, lindrig till medelsvår, långvarig, barn och ungdomar, 2017. Available: https://roi.socialstyrelsen. se/riktlinjer/nationella-riktlinjer-for-vard-vid-depression-ochangestsyndrom/2; https://www.socialstyrelsen.se/regler-ochriktlinjer/nationella-riktlinjer/om-nationella-riktlinjer/sa-tar-vi-framriktlinjerna/ [Accessed 31 Jan 2019].

22 Cleare A, Pariante CM, Young AH, et al. Evidence-based guidelines for treating depressive disorders with antidepressants: a revision of the 2008 British association for psychopharmacology guidelines. $J$ Psychopharmacol 2015;29:459-525.

23 Emslie G, Kratochvil C, Vitiello B, et al. Treatment for adolescents with depression study (TADS): safety results. J Am Acad Child Adolesc Psychiatry 2006;45:1440-55.

24 BMJ Best Practice. Depression in children. Available: https:// bestpractice.bmj.com/topics/en-gb/785?q=Depression [Accessed 30 Oct 2018].

25 Laukkanen E. Depression of adolescents: Duodecim medical publications Ltd, 2018. Available: https://www.ebm-guidelines.com/ $\mathrm{dtk} / \mathrm{ebmg} / \mathrm{home}$ ?id=ebm00703 [Accessed 30 Oct 2018].

26 The AGREE Next Steps Consortium. Appraisal of guidelines for research \& evaluation II (AGREE II), 2017. Available: https://www. agreetrust.org/agree-ii/ [Accessed 15 Aug 2019].

27 Loke YK, Price D, Herxheimer A, et al. Systematic reviews of adverse effects: framework for a structured approach. BMC Med Res Methodol 2007;7:32.

28 Zorzela L, Golder S, Liu Y, et al. Quality of reporting in systematic reviews of adverse events: systematic review. BMJ 2014;348:f7668.
29 Saini P, Loke YK, Gamble C, et al. Selective reporting bias of harm outcomes within studies: findings from a cohort of systematic reviews. BMJ 2014;349:g6501.

30 Cheung AH, Zuckerbrot RA, Jensen PS, et al. Guidelines for adolescent depression in primary care (GLAD-PC): part II. treatment and ongoing management. Pediatrics 2018;141:e20174082.

31 Kramer S, van Zuuren EJ, Ehrlich A. Depression in children and adolescents: DynaMed plus, EBSCO. Available: http://www. dynamed.com/topics/dmp AN T906140/Depression-in-childrenand-adolescents\#Overview-and-Recommendations [Accessed 3 Feb 2019].

32 MacQueen GM, Frey BN, Ismail Z, et al. Canadian network for mood and anxiety treatments (CANMAT) 2016 clinical guidelines for the management of adults with major depressive disorder: section 6 . special populations: youth, women, and the elderly. Can J Psychiatry 2016;61:588-603.

33 NICE National Institute for Health and Care Excellence. Depression in children and young people: identification and management (CG28), 2017. Available: https://www.nice.org.uk/guidance/cg28 [Accessed 3 Feb 2019].

34 Orygen The National Centre of Excellence in Youth Mental Health. Treating depression in young people 2017. Available: https://www. orygen.org.au/Education-Training/Resources-Training/Resources/ Free/Clinical-Practice/Treating-depression-in-yp [Accessed 5 May 2019].

35 New Zealand Guidelines Group. Identification of common mental disorders and management of depression in primary care. an evidence-based best practice guideline, 2008. Available: https:// www.health.govt.nz/publication/identification-common-mentaldisorders-and-management-depression-primary-care [Accessed 31 Jan 2019].

36 Regionsenter for barn og unges psykiske helse, Helseregion Øst og Sør. Mer om medikamentell behandling av barn og unge diagnostisert med depresjon. In: Håndbok for barn og unges psykiske helse, 2019.

37 Norsk barnelegeforening. Pediatriveilederen. Psykiske lidelser og psykososiale tilstander. 12.3 Angst og depresjon, 2018. Available: https://www.helsebiblioteket.no/pediatriveiledere? menuitemkeylev1=5962\&menuitemkeylev2=5975\&key $=144656$ [Accessed 1 Feb 2019].

38 Retsinformation. Vejledning om medikamentel behandling af børn og unge med psykiske lidelser: sundhedsstyrelsen, 2013. Available: https://www.retsinformation.dk/Forms/R0710.aspx?id=146409 [Accessed 31 Jan 2019].

39 Sørensen MJ, Kalvåg MB, Nøhr-Jensen P, et al. Landsdækkende klinisk retningslinje vedrørende udredning og behandling af depression hos børn og unge. Børne- og ungdomspsykiatrisk Selskab I Danmark, 2011. Available: http://www.bupnet.dk/kliniskeretningslinjer/depression-hos-b\%C3\%B8rn-og-unge [Accessed 31 Jan 2019].

40 Puura K. Childhood depression: Duodecim medical publications Ltd, 2016. Available: https://www.ebm-guidelines.com/dtk/ebmg/home? id=ebm00682 [Accessed 30 Oct 2018].

41 Bridge JA, lyengar S, Salary CB, et al. Clinical response and risk for reported suicidal ideation and suicide attempts in pediatric antidepressant treatment: a meta-analysis of randomized controlled trials. JAMA 2007;297:1683-96.

42 Barbui C, Esposito E, Cipriani A. Selective serotonin reuptake inhibitors and risk of suicide: a systematic review of observational studies. CMAJ 2009;180:291-7. 